\title{
Food availability, accessibility and dietary practices during the COVID-19 pandemic: a multi-country survey
}

\author{
Ali Jafri ${ }^{1, *}$ (D), Nonsikelelo Mathe ${ }^{2}$, Elom K Aglago ${ }^{3}$, Silvenus $\bigcirc$ Konyole ${ }^{4}$, \\ Moussa Ouedraogo ${ }^{5}$, Keiron Audain ${ }^{6}$, Urbain Zongo ${ }^{5}$, Amos K Laar ${ }^{7}$ (1), \\ Jeffrey Johnson ${ }^{2}$ and Dia Sanou ${ }^{8}$ \\ ${ }^{1}$ Mohammed VI University of Health Sciences, Université Mohammed VI des Sciences de la Santé, avenue Taieb \\ Naciri, Casablanca, Morocco: ${ }^{2}$ Alliance for Canadian Health Outcomes Research in Diabetes, University of Alberta, \\ Alberta, Canada: ${ }^{3}$ Nutrition and Metabolism Section, International Agency for Research on Cancer (IARC), Lyon, \\ France: ${ }^{4}$ Department of Nutritional Sciences, Masinde Muliro University of Science and Technology, Kakamega, \\ Kenya: ${ }^{5}$ Joseph Ki-Zerbo University, Ouagadougou, Burkina Faso: ${ }^{6}$ Department of Food Science and Nutrition, \\ University of Zambia, Lusaka, Zambia: ${ }^{7}$ University of Ghana, Accra, Ghana: ${ }^{8}$ Food and Agriculture Organization of \\ the United Nations, Addis Ababa, Ethiopia
}

Submitted 14 October 2020: Final revision received 25 February 2021: Accepted 1 March 2021: First published online 5 March 2021

\begin{abstract}
Objective: To investigate the perceived effects of the coronavirus disease (COVID-19) pandemic lockdown measures on food availability, accessibility, dietary practices and strategies used by participants to cope with these measures. Design: We conducted a cross-sectional multi-country online survey between May and July 2020. We used a study-specific questionnaire mainly based on the adaptation of questions to assess food security and coping strategies from the World Food Programme's 'Emergency Food Security Assessment' and 'The Coping Strategy Index'.

Setting: The questionnaire was hosted online using Google Forms and shared using social media platforms.

Participants: A total of 1075 adult participants from eighty-two countries completed the questionnaire.

Results: As a prelude to COVID-19 lockdowns, $62.7 \%$ of the participants reported to have stockpiled food, mainly cereals $(59.5 \%$ of the respondents) and legumes $(48.8 \%)$. An increase in the prices of staples, such as cereals and legumes, was widely reported. Price increases have been identified as an obstacle to food acquisition by $32.7 \%$ of participants. Participants reported having lesser variety (50.4\%), quality (30.2\%) and quantity (39.2\%) of foods, with disparities across regions. Vulnerable groups were reported to be facing some struggle to acquire adequate food, especially people with chronic diseases (20.2\%), the elderly (17.3\%) and children (14.5\%). To cope with the situation, participants mostly relied on less preferred foods (49\%), reduced portion sizes (30\%) and/or reduced the number of meals $(25.7 \%)$.

Conclusions: The COVID-19 pandemic negatively impacted food accessibility and availability, altered dietary practices and worsened the food insecurity situation, particularly in the most fragile regions.
\end{abstract}

\author{
Keywords \\ COVID-19 \\ Food availability \\ Accessibility \\ Nutrition security \\ Coping mechanisms
}

In March 2020, the WHO declared the novel coronavirus outbreak a pandemic. This pandemic started in December 2019 as a local public health issue in the city of Wuhan in China and quickly escalated to become an unprecedented global health situation. Responding to the pandemic, most countries instituted strict measures such as lockdowns which included self-isolation, quarantine, confinement and/or curfews to mitigate the spread of the disease.
As shown by previous experiences, global and regional emergencies can impact food and nutritional security in households and communities. In 2008, following the global economic crisis, food prices increased and created economic and social instabilities in several regions in the world, including higher income countries ${ }^{(1)}$. In 2014, the Western African Ebola virus disease outbreak had a significant impact on food security in most of the affected 
countries $^{(2)}$. Countries with strong and sustainable food systems usually recover from these crises. However, for those already faced with hunger and socio-economic challenges, the struggle can be more permanent ${ }^{(3)}$.

The relationship between diet-related diseases and food insecurity has been thoroughly investigated ${ }^{(4,5)}$. Individuals from food-insufficient households have significantly higher odds of having poor functional health, restricted activity and multiple chronic conditions (e.g. obesity, heart disease, diabetes and high blood pressure $)^{(6-8)}$. Also, food insecurity has been associated with major depression, distress and having poor social support ${ }^{(9,10)}$. Furthermore, food insecurity has been consistently associated with health problems in young children and toddlers ${ }^{(11,12)}$.

Since the beginning of the COVID-19 pandemic, lockdown measures have disrupted food systems globally and altered availability and access to healthy foods ${ }^{(13)}$. Early reports warned about the potential repercussions of interrupted food chains ${ }^{(14,15)}$. Lockdowns have been slowing harvest and impacting food industries, including the closure of businesses, burying perishable food products or dumping milk by farmers ${ }^{(16)}$. As a result of the supply chain disruption and the increasing consumer demand, the prices of basic foods have begun to rise ${ }^{(16)}$, which could negatively affect people's access to healthy foods and contribute to food insecurity and malnutrition ${ }^{(16)}$. Furthermore, the unavailability or reduced affordability of healthy foods might lead to greater consumption of ultra-processed and canned foods, which, combined with reduced physical activity, could worsen obesity and other diet-related noncommunicable disease.

While there is no doubt that COVID-19 lockdown measures might affect food security and nutrition, the implications of these lockdowns on the availability and accessibility of healthy food worldwide are poorly documented. Therefore, it is imperative to document the impacts of COVID-19 lockdowns on food security, including availability, accessibility and coping mechanisms, in different regions of the world. The current study was undertaken to investigate the perceived effects of COVID-19 lockdown measures on food availability and accessibility and key strategies that participants used to cope with those measures.

\section{Methodology}

\section{Development of the questionnaire}

The data used in the current study were collected through an online questionnaire. The questionnaire was developed using existing assessment tools and drawing on the expertise of the research team. The questionnaire (in English) was adapted from the World Food Programme's Emergency Food Security Assessment ${ }^{(17)}$ and the Coping Strategy Index ${ }^{(18)}$ and incorporated questions about food access, dietary changes and coping mechanisms during the COVID-19 pandemic. Then, the draft questionnaire was sent electronically to ten experts in nutrition, food science, public health and epidemiology to check the relevance, format and order of the questions. The team of experts were based in Burkina Faso, Canada, Ethiopia, France, Kenya, Morocco and Zambia. The final version of the questionnaire was translated into French and Arabic. It was structured to document the following areas: (i) government confinement and lockdown measures; (ii) food access; (iii) dietary and nutritional changes and (iv) sociodemographic information of the respondents.

\section{Piloting and sampling}

The questionnaire was created and administered via Google Forms. The questionnaire was sent electronically to a small number of volunteers from various countries ( $n$ 25) so that we may verify the content's validity of the questions and make amendments to the wording and positioning of the questions. In addition, the study team and the volunteers explored the sensitivity of the questions regarding specific dietary and lifestyle practices such as alcohol consumption, smoking and physical activity.

The link to the finalised survey was shared widely using diverse digital tools including email, Twitter, Facebook, WhatsApp and Reddit. In order to maximise participation and increase the response rate, a number of strategies were used to spread the information regarding the survey, particularly via national and international nutrition societies and networks. A bulk email was circulated to members with an active email account containing a link to the online survey. A reminder notice was sent via email in the following weeks to increase the response rate.

\section{Data management}

Coded data with no personal identifier were collected, exported and stored in password-protected computers. The data were used only for the intended research purposes and only the research team had access to it. The team checked the levels of completion by region and used this data to decide whether focus should be put on specific regions to recruit more participants.

\section{Data analysis}

Descriptive statistics were used to characterise the responses. Responses were analysed by geographical subregions. All the statistical analyses were performed using Stata 14.0 (StataCorp.).

\section{Results}

From May to June 2020, a total of 1075 respondents from eighty-two countries completed the questionnaires in English (62.4\%), in French (36.0 \%) and in Arabic (1.65\%). Respondents with missing entries ( $n$ 13) and duplicates 
Table 1 General characteristics of the study participants ( $n$ 1029)

\begin{tabular}{|c|c|c|c|c|c|c|c|c|}
\hline & $\begin{array}{l}\text { North } \\
\text { Africa }\end{array}$ & $\begin{array}{l}\text { West } \\
\text { Africa }\end{array}$ & $\begin{array}{c}\text { East } \\
\text { Africa }\end{array}$ & $\begin{array}{l}\text { Southern } \\
\text { Africa }\end{array}$ & $\begin{array}{l}\text { Western } \\
\text { Europe }\end{array}$ & $\begin{array}{l}\text { North } \\
\text { America }\end{array}$ & Other & Total \\
\hline $\begin{array}{l}\text { Total }(n) \\
\text { Gender }(\%)\end{array}$ & 136 & 251 & 146 & 83 & 172 & 105 & 136 & 1029 \\
\hline Female & 63.2 & 37.5 & $49 \cdot 3$ & $78 \cdot 3$ & 53.5 & $62 \cdot 0$ & 51.5 & 52.9 \\
\hline Male & $35 \cdot 3$ & $59 \cdot 8$ & $50 \cdot 0$ & $21 \cdot 7$ & $42 \cdot 4$ & $34 \cdot 3$ & $47 \cdot 1$ & 44.9 \\
\hline Undisclosed & 1.47 & $2 \cdot 79$ & 0.68 & 0 & 4.07 & 3.81 & 1.47 & $2 \cdot 14$ \\
\hline \multicolumn{9}{|l|}{ Location (\%) } \\
\hline Rural & $2 \cdot 21$ & $6 \cdot 37$ & $17 \cdot 1$ & 4.82 & $19 \cdot 8$ & 23.8 & $13 \cdot 2$ & $12 \cdot 2$ \\
\hline Suburban & 1.47 & 1.59 & 2.05 & 3.61 & 4.65 & $18 \cdot 1$ & 3.68 & $4 \cdot 28$ \\
\hline Urban & $96 \cdot 3$ & $92 \cdot 0$ & $80 \cdot 8$ & 91.6 & $75 \cdot 6$ & $58 \cdot 1$ & $83 \cdot 1$ & 83.6 \\
\hline \multicolumn{9}{|l|}{ Age } \\
\hline 1st quartile & $27 \cdot 0$ & $30 \cdot 0$ & $28 \cdot 0$ & $28 \cdot 0$ & $28 \cdot 0$ & 33.0 & $30 \cdot 0$ & $29 \cdot 0$ \\
\hline Median & 33.0 & $34 \cdot 0$ & $34 \cdot 0$ & $37 \cdot 0$ & 33.0 & $40 \cdot 0$ & $35 \cdot 0$ & $35 \cdot 0$ \\
\hline 3rd quartile & 40.5 & $41 \cdot 0$ & $42 \cdot 0$ & $42 \cdot 0$ & 40.5 & 48.0 & $40 \cdot 0$ & $42 \cdot 0$ \\
\hline \multicolumn{9}{|l|}{ Education (\%) } \\
\hline Primary & 0 & 0.4 & 1.37 & 0 & 0.59 & 0 & 0 & 0.39 \\
\hline Secondary & 3.68 & 4.78 & $4 \cdot 11$ & $9 \cdot 76$ & $11 \cdot 2$ & 11.5 & $5 \cdot 15$ & 6.73 \\
\hline University degree & $31 \cdot 6$ & 27.5 & $50 \cdot 7$ & 53.7 & $42 \cdot 9$ & $47 \cdot 1$ & 39.0 & 39.5 \\
\hline Master or PhD & 64.7 & $67 \cdot 3$ & $43 \cdot 8$ & $36 \cdot 6$ & $45 \cdot 3$ & 41.4 & 55.9 & 53.4 \\
\hline \multicolumn{9}{|l|}{ Employment (\%) } \\
\hline Student & $14 \cdot 0$ & 5.98 & 3.42 & 2.41 & $12 \cdot 8$ & 3.81 & $5 \cdot 15$ & $7 \cdot 19$ \\
\hline Employed & $80 \cdot 2$ & 89.6 & 84.3 & $89 \cdot 2$ & 79.1 & 78.1 & 89.7 & 84.7 \\
\hline Retired & $2 \cdot 21$ & 0.4 & 2.05 & $3 \cdot 61$ & $2 \cdot 33$ & 4.76 & $2 \cdot 21$ & $2 \cdot 14$ \\
\hline Unemployed & 1.47 & 3.59 & 7.53 & 4.82 & $5 \cdot 23$ & 7.62 & $2 \cdot 21$ & 4.47 \\
\hline $\begin{array}{l}\text { Unemployed due to } \\
\text { COVID }\end{array}$ & $2 \cdot 21$ & 0.4 & $2 \cdot 74$ & 0 & 0.58 & $5 \cdot 71$ & 0.74 & 1.55 \\
\hline \multicolumn{9}{|l|}{ Household income in USD } \\
\hline First quartile & 652.5 & 200 & 200 & 300 & 2000 & 3150 & 420 & 392.5 \\
\hline Median & 1600 & 500 & 590 & 1400 & 3600 & 8250 & 1000 & 1300 \\
\hline Third quartile & 3000 & 1000 & 1500 & 2500 & 8000 & 32500 & 3000 & 3900 \\
\hline \multicolumn{9}{|l|}{ COVID-19 security measures } \\
\hline Travel ban (\%) & $97 \cdot 8$ & 94.4 & $85 \cdot 6$ & 100 & 83.7 & $74 \cdot 3$ & $70 \cdot 6$ & $87 \cdot 1$ \\
\hline Lockdown (\%) & $81 \cdot 6$ & $80 \cdot 1$ & $86 \cdot 3$ & 81.9 & $14 \cdot 0$ & $12 \cdot 4$ & 33.8 & $57 \cdot 2$ \\
\hline Social distancing (\%) & 94.9 & $96 \cdot 4$ & $96 \cdot 6$ & $95 \cdot 2$ & $98 \cdot 8$ & 100 & 98.5 & $97 \cdot 2$ \\
\hline Home confinement (\%) & $95 \cdot 6$ & 49.4 & 51.4 & 89.2 & $77 \cdot 3$ & $56 \cdot 2$ & 69.9 & $67 \cdot 1$ \\
\hline Closed fast-foods (\%) & $80 \cdot 2$ & $57 \cdot 0$ & $48 \cdot 6$ & $72 \cdot 3$ & $73 \cdot 3$ & $58 \cdot 1$ & 53.7 & 62.5 \\
\hline Closed supermarkets (\%) & 7.35 & 37.9 & 6.85 & $12 \cdot 1$ & 4.65 & $5 \cdot 71$ & 14.7 & $15 \cdot 5$ \\
\hline
\end{tabular}

(i.e. repeat respondents) ( $n$ 33) were excluded from the analysis.

Table 1 summarises the characteristics of the 1029 respondents. The largest number of respondents were from West Africa (24.4\%), followed by West Europe (16.7\%), East Africa (14.2\%), North Africa (13.2\%), North America (10.2\%) and Southern Africa (8.07\%). Respondents had a median age of 35 years, were mostly living in urban areas $(83.4 \%)$, were married $(51.8 \%)$, had graduate education (84.7\%) and female respondents represented $52.9 \%$. A total of $85 \%$ of the respondents were employed, while $7 \cdot 2 \%$ were students. Respondents in North America reported the highest loss of jobs due to the COVID-19 pandemic $(5.7 \%)$.

Respondents reported that various security measures were in effect in their respective locations, and most $(62.7 \%)$ reported that they stockpiled food in anticipation of food shortages during the COVID-19-related lockdowns (Table 2). Cereals were the most stockpiled items (59.5\%), followed by legumes (48.8\%) and canned goods (38.8\%). Perishables like fruits and dairy products were stockpiled by fewer people. Geographically, more people from North America stockpiled food overall (76.2\%), especially canned goods (66.7\%). More people from West and East Africa particularly stockpiled cereals (77.7 and $74.7 \%$, respectively).

Respondents reported that the prices of food items increased during the lockdowns; the most commonly affected food groups were fruits and vegetables, cereals and meat (Table 3). Increased prices of staples like cereals were most commonly reported in African countries; $77.4 \%$ in East Africa, $61.4 \%$ in West Africa and $54.2 \%$ in Southern Africa. Price increases have been identified as an obstacle to food acquisition by $32.7 \%$ of respondents (Fig. 1). The impact of food price increase on food acquisition was more commonly reported by respondents in African countries, especially in East Africa (58.2\%).

The restrictive security measures instituted during the early months of the pandemic have affected the dietary habits of the respondents. The most commonly reported issue was access to a lesser variety of foods (Table 4), particularly in North America (74.3\%) and East Africa (63.7\%). Food quality and quantity were also a common concern, especially in East Africa (51.4 and 61.6\%, respectively). In order to counteract the effect of the restrictive public health measures on their diet, people resorted to alternative 
Table 2 Relative frequencies of respondents who stockpiled food during the COVID-19 pandemic during April and May 2020

\begin{tabular}{|c|c|c|c|c|c|c|c|c|}
\hline & North Africa & West Africa & East Africa & Southern Africa & Western Europe & North America & Other & Total \\
\hline Total $(n)$ & 136 & 251 & 146 & 83 & 172 & 105 & 136 & 1029 \\
\hline $\begin{array}{l}\text { Purchased more food due to } \\
\text { COVID-19 (\%) }\end{array}$ & 41.9 & $71 \cdot 3$ & $67 \cdot 1$ & 61.5 & $61 \cdot 1$ & $76 \cdot 2$ & $55 \cdot 2$ & $62 \cdot 7$ \\
\hline Stockpiled cereals (\%) & $50 \cdot 7$ & $77 \cdot 7$ & $74 \cdot 7$ & $39 \cdot 8$ & $40 \cdot 1$ & $56 \cdot 2$ & $57 \cdot 4$ & 59.5 \\
\hline Stockpiled meat (\%) & $29 \cdot 4$ & $42 \cdot 2$ & $36 \cdot 3$ & $45 \cdot 8$ & $22 \cdot 7$ & 43.8 & $36 \cdot 0$ & $36 \cdot 1$ \\
\hline Stockpiled dairy (\%) & $18 \cdot 4$ & $45 \cdot 4$ & $16 \cdot 4$ & 14.5 & 8.72 & $20 \cdot 0$ & $30 \cdot 9$ & $24 \cdot 6$ \\
\hline Stockpiled legumes (\%) & 43.4 & $55 \cdot 0$ & $69 \cdot 2$ & 37.4 & 35.5 & $48 \cdot 6$ & 44.9 & $48 \cdot 8$ \\
\hline Stockpiled fruits (\%) & $15 \cdot 4$ & $20 \cdot 3$ & $23 \cdot 3$ & $22 \cdot 9$ & $7 \cdot 6$ & 30.5 & $19 \cdot 1$ & $19 \cdot 1$ \\
\hline Stockpiled vegetables (\%) & $21 \cdot 3$ & $42 \cdot 2$ & 29.5 & 33.7 & $14 \cdot 0$ & $37 \cdot 1$ & $30 \cdot 9$ & $30 \cdot 2$ \\
\hline $\begin{array}{l}\text { Stockpiled canned } \\
\text { products (\%) }\end{array}$ & $35 \cdot 3$ & $39 \cdot 8$ & $16 \cdot 4$ & $41 \cdot 0$ & $44 \cdot 8$ & $66 \cdot 7$ & 33.8 & $38 \cdot 8$ \\
\hline Stockpiled sweets (\%) & $19 \cdot 1$ & $18 \cdot 7$ & $13 \cdot 7$ & $15 \cdot 7$ & 14.5 & $24 \cdot 8$ & 19.9 & 17.9 \\
\hline
\end{tabular}

Table 3 Relative frequency of people having experienced increasing prices in certain food groups, alcohol and cigarettes during the COVID-19 pandemic

\begin{tabular}{|c|c|c|c|c|c|c|c|c|}
\hline & North Africa & West Africa & East Africa & Southern Africa & Western Europe & North America & Other & Total \\
\hline Total $(n)$ & 136 & 251 & 146 & 83 & 172 & 105 & 136 & 1029 \\
\hline Cereals (\%) & $24 \cdot 3$ & 61.4 & 77.4 & $54 \cdot 2$ & $25 \cdot 0$ & $28 \cdot 6$ & $50 \cdot 7$ & $47 \cdot 3$ \\
\hline Dairy (\%) & 8.82 & 37.5 & $45 \cdot 9$ & $50 \cdot 6$ & $19 \cdot 8$ & 41.9 & 41.9 & $34 \cdot 0$ \\
\hline Fruits and veggies (\%) & 43.4 & $62 \cdot 6$ & 65.8 & $62 \cdot 7$ & 29.7 & 32.4 & $58 \cdot 8$ & 51.4 \\
\hline Meats (\%) & $27 \cdot 2$ & 53.4 & $50 \cdot 0$ & $62 \cdot 7$ & 24.4 & 61.9 & $47 \cdot 1$ & $45 \cdot 4$ \\
\hline Legumes (\%) & $28 \cdot 7$ & $52 \cdot 2$ & $67 \cdot 1$ & $47 \cdot 0$ & $16 \cdot 9$ & $18 \cdot 1$ & $40 \cdot 4$ & $39 \cdot 8$ \\
\hline Oils and fats (\%) & $14 \cdot 0$ & 39.8 & $52 \cdot 1$ & $54 \cdot 2$ & $14 \cdot 0$ & $18 \cdot 1$ & $34 \cdot 6$ & $32 \cdot 1$ \\
\hline Sweets (\%) & 9.56 & $36 \cdot 3$ & $50 \cdot 7$ & $51 \cdot 8$ & $14 \cdot 0$ & $12 \cdot 4$ & $39 \cdot 0$ & $30 \cdot 2$ \\
\hline Alcohol (\%) & $12 \cdot 3$ & $11 \cdot 7$ & $15 \cdot 7$ & $25 \cdot 0$ & 7.38 & $11 \cdot 1$ & $23 \cdot 0$ & $12 \cdot 8$ \\
\hline Cigarettes (\%) & 6.56 & 4.04 & $9 \cdot 8$ & $25 \cdot 0$ & $4 \cdot 7$ & 4.94 & 6.90 & 6.00 \\
\hline
\end{tabular}

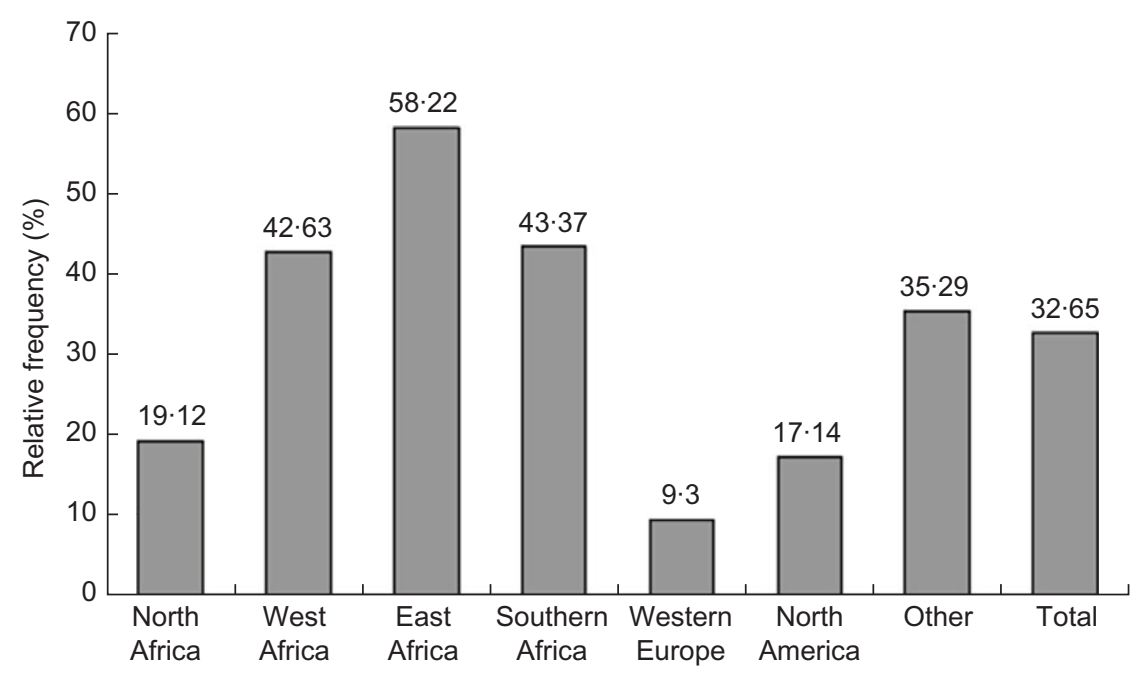

Fig. 1 Relative frequency of people whose food acquisition has been affected by price increases during COVID-19

approaches such as relying on other foods ( $49 \cdot 2 \%$ ) or reducing portion sizes $(30.3 \%)$ (Table 4$)$. These coping mechanisms were more frequent in African countries, especially East Africa where more respondents reported having to borrow food (32.9\%), reduce portion sizes $(50.7 \%)$, reduce the number of meals (45.9\%) and/or rely on food aid (18.5\%).

Vulnerable groups reported challenges in acquiring adequate foods (Table 5), especially people living with chronic diseases (20.2\%), the elderly (17.3\%) and children $(14.5 \%)$.

\section{Discussion}

In the current study, we documented the changes in food accessibility and availability globally as a result of the COVID-19 pandemic lockdowns which restricted the 
Table 4 Aspects of food insecurity experienced by the study participants and coping mechanisms adopted during the COVID-19 pandemic

\begin{tabular}{|c|c|c|c|c|c|c|c|c|}
\hline & $\begin{array}{l}\text { North } \\
\text { Africa }\end{array}$ & $\begin{array}{l}\text { West } \\
\text { Africa }\end{array}$ & $\begin{array}{c}\text { East } \\
\text { Africa }\end{array}$ & $\begin{array}{l}\text { Southern } \\
\text { Africa }\end{array}$ & $\begin{array}{l}\text { Western } \\
\text { Europe }\end{array}$ & $\begin{array}{c}\text { North } \\
\text { America }\end{array}$ & Other & Total \\
\hline Total $(n)$ & 136 & 251 & 146 & 83 & 172 & 105 & 136 & 1029 \\
\hline \multicolumn{9}{|l|}{ Aspects of food insecurity } \\
\hline $\begin{array}{l}\text { Difficulty accessing drinking } \\
\text { water (\%) }\end{array}$ & 1.47 & $11 \cdot 6$ & $19 \cdot 9$ & 8.43 & $1 \cdot 16$ & $4 \cdot 76$ & $14 \cdot 0$ & 9.04 \\
\hline Lesser variety of food (\%) & $19 \cdot 1$ & $41 \cdot 0$ & $63 \cdot 7$ & 61.5 & $56 \cdot 4$ & 74.3 & $52 \cdot 2$ & $50 \cdot 4$ \\
\hline Food of less quality (\%) & $10 \cdot 3$ & $29 \cdot 1$ & 51.4 & $26 \cdot 5$ & $20 \cdot 9$ & $38 \cdot 1$ & 37.5 & $30 \cdot 2$ \\
\hline Lesser quantity of food (\%) & 8.82 & 35.9 & 61.6 & $51 \cdot 8$ & $40 \cdot 7$ & 49.5 & 33.8 & 39.2 \\
\hline Subject to food rationing (\%) & $6 \cdot 62$ & $14 \cdot 3$ & $19 \cdot 2$ & $27 \cdot 7$ & 7.56 & 7.62 & $16 \cdot 9$ & $13 \cdot 6$ \\
\hline Food less accessible (\%) & $16 \cdot 2$ & 23.9 & $39 \cdot 0$ & $15 \cdot 7$ & $12 \cdot 8$ & $25 \cdot 7$ & $20 \cdot 6$ & $22 \cdot 3$ \\
\hline Not having any food all day (\%) & 5.47 & 9.56 & $24 \cdot 7$ & 4.82 & 2.33 & 9.52 & 11.0 & 9.79 \\
\hline Eating less frequently (\%) & $19 \cdot 5$ & $23 \cdot 1$ & $45 \cdot 9$ & $31 \cdot 3$ & $11 \cdot 1$ & 29.5 & $26 \cdot 5$ & $25 \cdot 7$ \\
\hline \multicolumn{9}{|l|}{ Coping mechanisms } \\
\hline $\begin{array}{l}\text { Relying on less preferred } \\
\text { food }(\%)\end{array}$ & $28 \cdot 9$ & $40 \cdot 2$ & $67 \cdot 1$ & 67.5 & $43 \cdot 6$ & $65 \cdot 7$ & 48.5 & $49 \cdot 2$ \\
\hline Borrowing food (\%) & $12 \cdot 5$ & $14 \cdot 3$ & 32.9 & $16 \cdot 9$ & 13.4 & $12 \cdot 4$ & $17 \cdot 7$ & $17 \cdot 0$ \\
\hline Food credit (\%) & $10 \cdot 9$ & 13.9 & $36 \cdot 3$ & $18 \cdot 1$ & 4.65 & $19 \cdot 1$ & $14 \cdot 7$ & $16 \cdot 2$ \\
\hline Reducing portion sizes (\%) & $19 \cdot 5$ & $28 \cdot 3$ & $50 \cdot 7$ & 34.9 & $19 \cdot 8$ & 31.4 & $31 \cdot 6$ & $30 \cdot 3$ \\
\hline Adults restricting themselves (\%) & 7.03 & $23 \cdot 1$ & $42 \cdot 5$ & $18 \cdot 1$ & $5 \cdot 81$ & 10.5 & $19 \cdot 1$ & $18 \cdot 7$ \\
\hline Reducing number of meals (\%) & 19.5 & $23 \cdot 1$ & $45 \cdot 9$ & $31 \cdot 3$ & $11 \cdot 1$ & 29.5 & $26 \cdot 5$ & $25 \cdot 7$ \\
\hline Food aid (\%) & 3.91 & 8.76 & 18.5 & 6.02 & 4.65 & $9 \cdot 52$ & $5 \cdot 88$ & 8.33 \\
\hline
\end{tabular}

Table 5 Vulnerable groups whose diets have been affected by COVID-19 restrictions

\begin{tabular}{|c|c|c|c|c|c|c|c|c|}
\hline & North Africa & West Africa & East Africa & Southern Africa & Western Europe & North America & Other & Total \\
\hline Total $(n)$ & 136 & 251 & 146 & 83 & 172 & 105 & 136 & 1029 \\
\hline Infants & 4.41 & 8.37 & 18.5 & $7 \cdot 23$ & 0.58 & $5 \cdot 71$ & $11 \cdot 8$ & 8.07 \\
\hline Children & $0 \cdot 15$ & $15 \cdot 9$ & $35 \cdot 6$ & $15 \cdot 7$ & $2 \cdot 91$ & $6 \cdot 67$ & $18 \cdot 4$ & $14 \cdot 5$ \\
\hline Pregnant women & $5 \cdot 88$ & $13 \cdot 2$ & $32 \cdot 2$ & $13 \cdot 3$ & $1 \cdot 16$ & $3 \cdot 81$ & $16 \cdot 2$ & $12 \cdot 3$ \\
\hline Breastfeeding women & 2.94 & $12 \cdot 4$ & $30 \cdot 1$ & 9.64 & 0.58 & 3.81 & $13 \cdot 2$ & $10 \cdot 7$ \\
\hline Elderly & 9.56 & $15 \cdot 9$ & 37.0 & $19 \cdot 3$ & $6 \cdot 98$ & $10 \cdot 5$ & 23.5 & $17 \cdot 3$ \\
\hline People with NCDs & $10 \cdot 3$ & $19 \cdot 9$ & $41 \cdot 1$ & $24 \cdot 1$ & $11 \cdot 1$ & $15 \cdot 2$ & $21 \cdot 3$ & $20 \cdot 2$ \\
\hline
\end{tabular}

movement of people and goods. Specifically, we have shown that the lockdowns were accompanied by a reduced food diversity, a change in places where food was acquired and an increase in the stockpiling of cereals and other non-perishable foods (e.g. canned goods). In addition, our findings showed geographical disparities in the fluctuation of food prices and the nature of coping mechanisms during the COVID-19 pandemic.

Our study is one of a handful of studies documenting changes in food accessibility and availability during the early months of the COVID-19 pandemic and confirms the global impact of lockdowns on food availability and accessibility. Participants reported experiencing some forms of food insecurity, with over $50 \%$ having access to lesser varieties of food, up to $74 \%$ in North America. A study on the early impact of COVID-19 in the USA suggests that there was nearly a one-third increase (32.3\%) in household food insecurity due to COVID-19 ${ }^{(19)}$. Food insecure participants experienced more challenges accessing food and utilising coping strategies ${ }^{(19)}$.

\section{Stockpiling of cereals and canned foods}

The COVID-19 lockdowns triggered the shortages of staple foods due to bulk buying and stockpiling. Our study showed that, in all regions, respondents reported an increase in stockpiling cereals, legumes and canned products. This may lead to a greater consumption of processed and canned foods due to the unavailability or reduced affordability of healthier foods. A study in Ethiopia using macro-economic data showed that urban trade for high value, nutritionally rich foods such as fruits and vegetables was reduced. Additionally, post-harvest loss, market price increases and urban demand for nutritious commodities declined during the early days of the pandemic ${ }^{(20)}$. Consequently, dietary diversity declined. In Addis Ababa, for example, households were consuming less fruit ( $81 \%$ declined to $60 \%$ ), meat ( $65 \%$ declined to $54 \%$ ) and dairy $(56 \% \text { declined to } 45 \%)^{(21)}$.

\section{Food prices}

Participants reported changes in the price of food items, particularly those of fruits, vegetables, cereals and meat in African countries. Whilst it is uncertain how food prices will evolve should the pandemic persist to the end of 2021, it was predicted before COVID-19 that food imports may decline by $13 \%$ at best and up to $25 \%$ in the worst-case scenario ${ }^{(22)}$. This prediction was explained by higher transaction costs and reduced domestic demand. A decline in 
imports can lead to increased prices and a shortage of basic consumer goods, which may result in an increased inflation in some countries ${ }^{(22)}$.

\section{Dietary and lifestyle changes}

Findings of this multi-country survey support previous findings of reported COVID-19-related dietary changes ${ }^{(23)}$. For example, Scarmozzino and Visioli ${ }^{(23)}$ reported that about $50 \%$ of adult respondents modified their diet during the lockdown, with $46.1 \%$ eating more and $19.5 \%$ having gained weight. A global survey including 1047 respondents from Asia (36\%), Africa (40\%), Europe (21\%) and other regions $(3 \%)$ reported unhealthier food consumption patterns including changing types of food, compulsive eating, snacking between meals and increased number of main meals during lockdown ${ }^{(24)}$. Lockdowns may have resulted in an increased use of alcohol and other substances due to solitude. However, rules regarding the access and purchase of alcohol differed by country. For example, in South Africa, the lockdown included a ban on alcohol and cigarette sales. Interestingly, other studies reported a decrease in alcohol consumption ${ }^{(23,25)}$.

\section{Health implications}

In the current study, some participants reported having trouble accessing drinkable water, eating less frequently and subject to reduced food diversity and quality. These changes can affect nutritional status, health and wellbeing ${ }^{(26)}$. Indeed, the nutritional status of individuals is associated with their capacity to resist infectious diseases; it is well known that the immune system is affected by malnutrition ${ }^{(26)}$. Nutrient intake has a definite relationship with antibody synthesis and the development of the immune system $^{(27)}$. Consequently, a compromised nutritional status could lower the body's ability to resist COVID-19 infection. Additionally, unhealthy dietary choices accompanied by a sedentary lifestyle could increase the incidence of noncommunicable diseases. COVID-19 lockdowns have been associated with a more sedentary lifestyle ${ }^{(28)}$ which could increase the risk of obesity and related non-communicable diseases. However, a study conducted in Italy with 3533 participants reported that although $48.6 \%$ of respondents perceived themselves as having gained weight, 38.3\% reported an increase in physical activity, especially body weight training, while $15 \%$ of respondents reported purchasing organic fruits and vegetables and $3 \%$ reported quitting smoking ${ }^{(29)}$. The overall health impact of COVID-19 lockdowns may only be apparent in the long-term.

\section{Policy implications}

During crisis, the first action should be to create emergency livelihoods and food assistance intervention to guarantee food access to the most vulnerable. Emergency livelihoods is an adaptation of livelihood intervention to respond to the immediate need of the most vulnerable populations in times of crisis. Examples of interventions include emergency short-term employment/cash-for-work tailored to COVID-19 prevention measures such as building and rehabilitating sanitation of public areas, disinfection and cleaning of public buildings, provision of food assistance and financial grants for the most vulnerable households. COVID-19 has created new vulnerable groups such as casual workers, small business owners and private sector employees who lost their jobs and income. The list of beneficiaries of food and social assistance programmes should be adjusted to include these new vulnerable groups. The changes in food prices affect these new vulnerable groups; therefore, policies to improve access to nutritious foods are important. Additionally, as the COVID-19 pandemic persists, the provision of food assistance may not be sustainable. It is, therefore, important to promote long-term livelihood and resilience building solutions that will help the vulnerable to start economic activities and to sustain livelihoods and be self-sufficient.

Sustained progress towards achieving the sustainable development goals may help combat current and future crises $^{(30)}$. The ongoing global agenda for food systems transformation, which aims to accelerate the achievement of sustainable development goals, should consider policy measures that facilitate immediate access to food for the most vulnerable and provide social protection programmes together with efficient food distribution in time of crisis. Governments should promote and develop capacities for innovative food distribution approaches such as the establishment of food hubs, mobile sales and e-commerce platforms or informal networks.

The rise in the price of the most nutritious food groups, such as fruits and vegetables, alongside reduced physical activity, due to home confinement and unemployment, may increase the prevalence of overweight and obesity and related non-communicable diseases. Access to accurate food price information should be prioritised as a policy response, in addition to instituting price control measures that aim to reduce the burden on the most affected. Further, governments should enhance food price monitoring and strengthen enforcement of violation of food price regulations. Food production, distribution and marketing should be monitored using rapid and repeated assessment tools in order to provide real-time information to evaluate the impacts on food security and inform post-COVID-19 recovery and management of future crises. The information can be disseminated through different channels including radio and social media. Such information provides opportunities for awareness campaigns on good food hygiene practices and nutritive value of different foods together with COVID-19 preventive measures.

Overall, while governments should be taking actions to mitigate the negative effects of restrictive measures on accessibility to nutritious food, maintaining social distancing measures will help prevent the food systems processes from becoming a source of propagation of the disease itself. 
Our study has several strengths, including the use of empirical data and the ability to analyse data from diverse geographical regions. Nevertheless, the main limitation of our study is that our sample included mainly respondents with Internet access, high degrees and jobs, criteria that would somewhat constitute a middle class. Therefore, our results cannot be widely extrapolated beyond the scope of the current study. Interestingly, for some countries and regions, the fact that we observed high levels of food insecurity as a result of COVID-19 lockdowns among those in the population who are employed might be considered an indicator that the situation is probably worse in the lower economic strata of these populations. Also, it is likely that the food classifications used in the current study might not have the same definitions across countries. It is possible that the selection by the respondents of food items such as sweets or dairy may relate to diverse food items across countries. Likewise, other terms such as rural and urban may have different definitions across countries. Additionally, the country and regional differences in lockdown measures and food systems may mean populations may not experience these measures in the same manner and the coping mechanisms may also vary.

In conclusion, food insecurity has been recorded in all surveyed countries; participants reported struggling with insufficient and inadequate food. Alongside reduced physical activity due to home confinement and unemployment, there is a great risk that the repercussions might include an increased prevalence of non-communicable diseases and malnutrition. The data presented in the current study highlight the fragility of global food systems during the COVID-19 pandemic. There is an urgent need to rethink how we produce, process, market and consume our food to create more sustainable and resilient food systems that protect livelihoods in the face of vulnerabilities and crises, which may impact people's ability to have access to healthier diets.

Subsequent surveys should also be planned in all countries in order to assess the impact of all the circumstances related to COVID-19 on populations' health and nutritional status.

\section{Acknowledgements}

Acknowledgements: The authors would like to thank all the participants who completed the questionnaire, and all the volunteers who helped in sharing the questionnaire with their network, especially Ms Michele Matta, Mr Teko Lantchible and Mr Boyodi Assanti. The authors are especially grateful for the support provided by the community networks such as African Nutrition Leadership Programme (ANLP), Agriculture-Nutrition Community of Practice (ag2nut), the Platform for African - European Partnership in Agricultural Research for Development (PAEPARD) and the African Nutrition Society (ANS). ACHORD, Alliance for Canadian Health Outcomes Research in Diabetes.
Financial support: This research received no specific grant from any funding agency in the public, commercial or not-for-profit sectors. Conflict of interest: There are no conflicts of interest. Authorship: Conceptualisation: A.J., E.K.A. and D.S. Data curation: A.J., E.K.A., M.O. and U.Z. Formal analysis: A.J. and E.K.A. Funding acquisition: N/A. Investigation: All authors. Methodology: All authors. Project administration: A.J., N.M., E.K.A. and D.S. Resources: All authors. Software: E.K.A. Supervision: A.J., N.M. and E.K.A. Validation: A.J., N.M. and E.K.A. Visualisation A.J., N.M. and E.K.A. Writing - original draft: A.J., D.S., K.A., SK, E.K.A. and N.M. Writing - review and editing: All authors. Ethics of human subject participation: The current study was conducted according to the guidelines laid down in the Declaration of Helsinki, and all procedures involving research study participants were approved by the Health Research Ethics Board of the University of Alberta (Study ID Pro00100418). Informed consent was obtained from all subjects using an online form.

\section{References}

1. FAO (2009) The State of Food Insecurity in the World Economic Crises - Impacts and Lessons Learned. Rome: Food and Agriculture Organization of the United Nations.

2. Thomas AC, Nkunzimana T, Perez Hoyos A et al. (2014) Impact of the West African Ebola Virus Disease Outbreak on Food Security. JRC Science and Policy Reports. Italy: ISPRA.

3. FAO (2020) Haiti Response Overview. Rome: FAO.

4. Olson CM (1999) Nutrition and health outcomes associated with food insecurity and hunger. J Nutr 129, 521S-524S.

5. Stuff JE, Casey PH, Szeto KL et al. (2004) Household food insecurity is associated with adult health status. J Nutr 134, 2330-2335.

6. Sun Y, Liu B, Rong S et al. (2020) Food insecurity is associated with cardiovascular and all-cause mortality among adults in the United States. J Am Heart Assoc 9, 14629.

7. Mendy VL, Vargas R, Cannon-Smith G et al. (2018) Food insecurity and cardiovascular disease risk factors among Mississippi adults. Int J Environ Res Public Health 15, 2016.

8. Gregory CA \& Coleman-Jensen A (2017) Food Insecurity, Chronic Disease, and Health among Working-Age Adults. Economic Research Report No 235. U.S Department of Agriculture, Economic Research Service. Washington, D.C.: United States Department of Agriculture.

9. Vozoris NT \& Tarasuk VS (2003) Household food insufficiency is associated with poorer health. J Nutr 133, 120-126.

10. Whitaker RC, Phillips SM \& Orzol SM (2006) Food insecurity and the risks of depression and anxiety in mothers and behavior problems in their preschool-aged children. Pediatrics 118, e859-e868.

11. Cook JT, Frank DA, Berkowitz C et al. (2004) Food insecurity is associated with adverse health outcomes among human infants and toddlers. J Nutr 134, 1432-1438.

12. Skalicky A, Meyers AF, Adams WF et al. (2006) Child food insecurity and iron deficiency anemia in low-income infants and toddlers in the United States. Matern Child Health J 10, $177-185$.

13. World Bank (2020) Food security and COVID-19 [Internet] Available at https://www.worldbank.org/en/topic/agriculture/ brief/food-security-and-covid-19 (accessed September 2020).

14. FAO (2020) COVID-19 and Smallholder Producers' Access to Markets. Rome: FAO. 
15. FSIN (2020) Global Report on Food Crises. Italy: FSIN.

16. UN (2020) Policy Brief: Impact of COVID-19 on Food Security and Nutrition. Rome: UN.

17. WFP (2009) Emergency Food Security Assessment Handbook, 2nd ed. Rome: World Food Programme.

18. Maxwell D \& Caldwell R (2008) The Coping Strategies Index: Field Methods Manual, 2nd ed. New York: Care International.

19. Niles MT, Bertmann F, Belarmino EH et al. (2020) The early food insecurity impacts of covid-19. Nutrients 12, 1-23.

20. Seneshaw T, Hirvonen K \& Minten B (2020) Impacts of the COVID-19 crisis on vegetable value chains in Ethiopia [Internet]. IFPRI; available at https://www.ifpri. org/blog/impacts-covid-19-crisis-vegetable-value-chainsethiopia (accessed September 2020).

21. Hirvonen K, Abate GT \& de Brauw A (2020) Food and Nutrition Security in Addis Ababa, Ethiopia during COVID-19 Pandemic. Addis Ababa: IFPRI.

22. Calderon C, Kambou G, Zebaze D et al. (2020) Africa's Pulse, No. 21, Sping 2020: An Analysis of Issues Shaping Africa's Economic Future. Washington, DC: World Bank.

23. Scarmozzino F \& Visioli F (2020) Covid-19 and the subsequent lockdown modified dietary habits of almost half the population in an Italian sample. Foods $\mathbf{9}, 675$.
24. Ammar A, Brach M, Trabelsi K et al. (2020) Effects of COVID-19 home confinement on eating behaviour and physical activity: results of the ECLB-COVID19 international online survey. Nutrients 12, 1583.

25. Zupo R, Castellana F, Sardone R et al. (2020) Preliminary trajectories in dietary behaviors during the COVID-19 pandemic: a public health call to action to face obesity. Int $J$ Environ Res Public Health 17, 7073.

26. Scrimshaw NS \& SanGiovanni JP (1997) Synergism of nutrition, infection, and immunity: an overview. Am J Clin Nutr 66, 464S-477S

27. Katona P \& Katona-Apte J (2008) The interaction between nutrition and infection. Clin Infect Dis $\mathbf{4 6}$, 1582-1588.

28. Zheng C, Huang WY, Sheridan S et al. (2020) COVID-19 pandemic brings a sedentary lifestyle in young adults: a cross-sectional and longitudinal study. Int J Environ Res Public Health 17, 6035.

29. Di Renzo L, Gualtieri P, Pivari F et al. (2020) Eating habits and lifestyle changes during COVID-19 lockdown: an Italian survey. J Transl Med 18, 229.

30. Heggen K, Sandset TJ \& Engebretsen E (2020) COVID-19 and sustainable development goals. Bull World Health Organ 98, 646 . 